\title{
Velocity Field Characteristics at the Inlet to a Pipe Culvert
}

\author{
Tomasz Kolerski, Paweł Wielgat \\ Gdańsk University of Technology, Faculty of Civil and Environmental Engineering, \\ ul. G. Narutowicza 11/12, 80-233 Gdańsk, Poland, e-mail: tomasz.kolerski@ wilis.pg.gda.pl
}

(Received September 22, 2014; revised October 09, 2014)

\begin{abstract}
A poorly designed culvert inlet structure causes scouring, which can lead to the collapse of the culvert and significant damage to the neighboring land. A set of laboratory tests was evaluated to examine velocity distribution at the culvert inlet. A three-dimensional acoustic Doppler velocimeter was used to measure instantaneous flow velocity upstream of the culvert. The analysis of mean velocities, turbulence strength, and Reynolds stresses was performed to understand the flow structure near the culvert entrance.
\end{abstract}

Key words: Culvert, Acoustic Doppler Velocitymeter, velocity field, turbulence

\section{Notation}

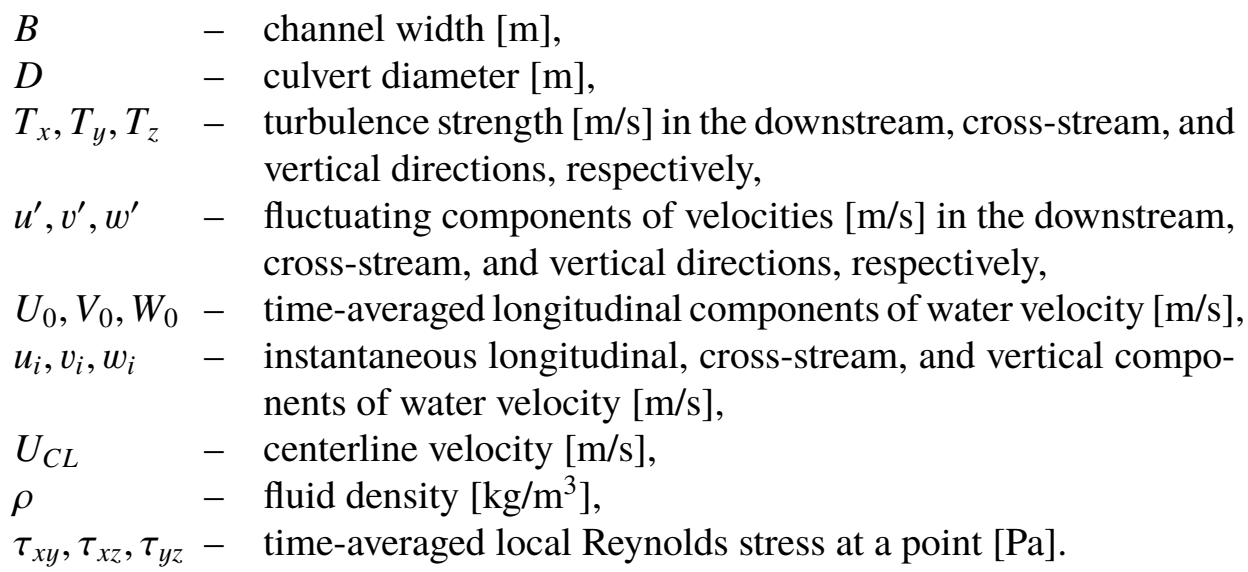

\section{Introduction}

Culverts are the most commonly used engineering structures for convoying storm water through a roadway or other area used for other purposes. Culvert design and 
hydraulic calculations are well established, and are not an issue from the engineering point of view. Some computer programs are capable of calculating culvert conveyance, which can be used in the designing process. However, if poorly designed, the culvert structure can be undermined by scouring at both the upstream and downstream ends, which may eventually lead to the destruction of the culvert, resulting in significant damage to nearby structures with high costs of rebuilding and repair of possible flood damage (Fig. 1). The inlet and outlet structures should be properly selected to prevent culvert damage due to erosion. In engineering practice, no specific calculations for these structures are made, and the selection of a particular solution is based mostly on the designers experience. In conveyance calculations, inlet structures are included by relevant coefficients provided by literature (Mays 2005, Kubrak and Kubrak 2004, Szpakowski 2013). This paper investigates the velocity distribution in the immediate vicinity of the culvert inlet by means of a set of laboratory experiments.

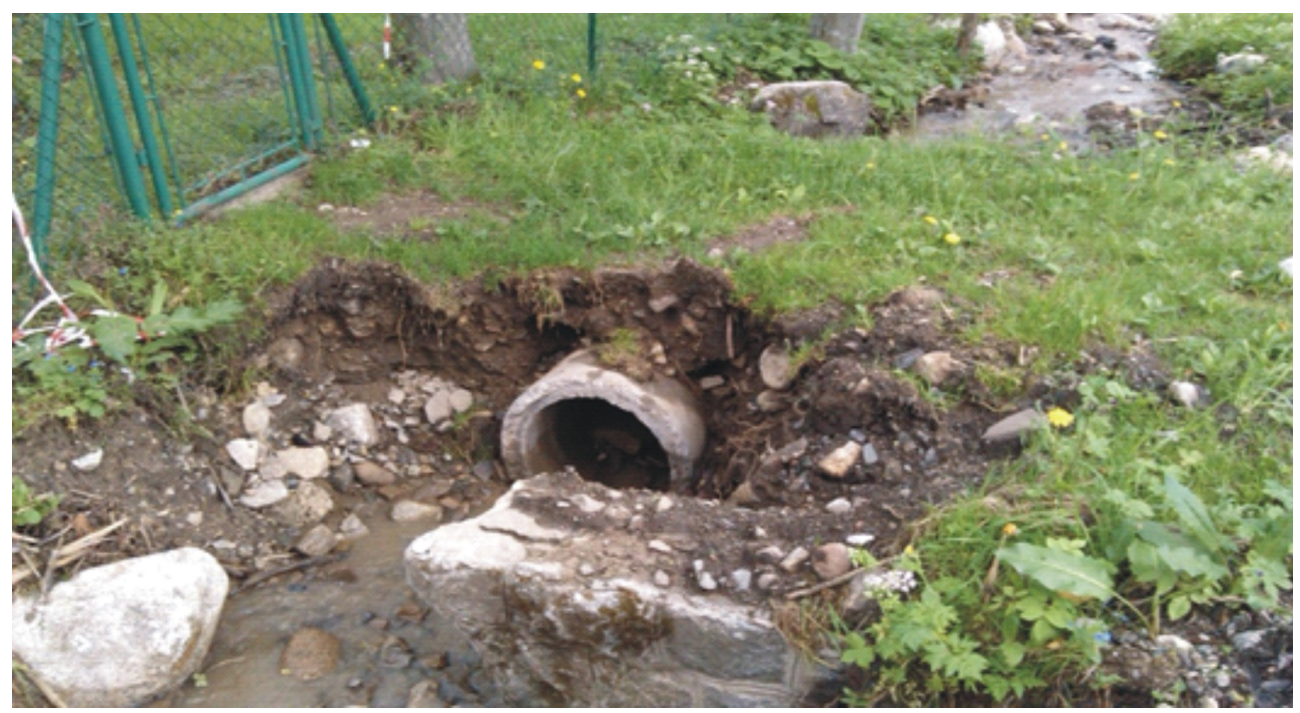

Fig. 1. Scour caused by storm water at aculvert inlet (Kuźnice, Poland, May 28, 2014)

Bed erosion is a consequence of high flow velocity in the direction opposite to the river bed. If the instantaneous drag force caused by water velocity is prevailing in the force balance acting on the submerged sediment, the sediment particles will be set in motion. This sediment transport in alluvial rivers may lead to bed scour. This process will be more intense if the river bed is built of fine material, which is more susceptible to transportation by flowing water. Van Rijn (1984) defined three stages of sediment transport in relation to the bed shear velocity: rolling and sliding, saltation, and suspended particle motion. The first two mechanisms are usually regarded as bed-load transport. The bed-load transport will initiate when the bed shear velocity exceeds the critical value. According to this rule, the Shields curve was derived (Shields, 1936), 
showing the threshold values for the initiation of motion for sediment of various sizes and Reynolds numbers. The Shields curve is most widely used to determine the critical condition for sediment movement.

The velocity filed inside the culvert barrel was examined by Ead et al (2000), House et al (2005), Hunt et al (2011), and Feurich et al (2013), to determine suitable conditions for fish passage. A number of papers have been published on erosion and sediment movement at the culvert outlet. Abt et al (1985 and 1987) investigated culvert geometry and the effect of slope on outlet scour. Doehring and Abt (1994) determined how the fall distance, or the drop height, beneath the culvert outlet affects the dimensions of local scour. Liriano et al (2002) analyzed the turbulent flow structure in scour holes downstream of the pipe culvert. Day (1997) observed turbulence ina vertical wall culvert, using a two-dimensional current meter. The effect of velocity on bed erosion at the culvert entrance for two inlet types will be investigated in this paper.

\section{Experimental Facilities}

Experiments were conducted in a $L=10 \mathrm{~m}$ long, $B=0.37 \mathrm{~m}$ wide, and $H=0.5 \mathrm{~m}$ deep channel at the hydraulic laboratory of the Gdańsk University of Technology. The open channel, in which the experiments were carried out, was situated in a closed loop system with flows up to a maximum of $0.120 \mathrm{~m}^{3} / \mathrm{s}$ being delivered from a sump along a supply pipeline and into the channel. Water then passed through a culvert and exhausted back into the main sump (Fig. 2). The main purpose of the sump was to clear the fluid of the suspended sediment and other organic material in order to improve the quality of the water. For the acoustic Doppler technique, sediment is necessary to produce signal reflection. Therefore, the suspension of the sediment, which settled on the bottom of the reservoir, was needed. This was achieved by walking in the sump for a period of time immediately before the tests. Flow measurements were carried out in the derivation channel with a pre-calibrated V-shaped sharp-crested weir flowmeter. Fig. 2 shows the open channel with the culvert installed and the supply system. The channel has no slope, and the flow is stimulated by a pump.

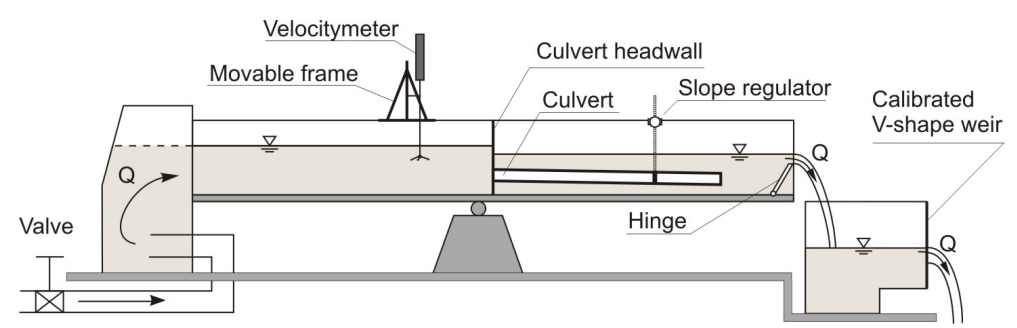

Fig. 2. Laboratory layout of the model culvert (longitudinal view) 
A pipe culvert $2.100 \mathrm{~m}$ in length and $0.1 \mathrm{~m}$ in internal diameter was made of 5 $\mathrm{mm}$ Plexiglas. The pipe was installed in the channel with the upstream end of the culvert fixed in a head wall. The ratio of the channel width to the culvert diameter, $B / D$, was therefore 3.7. The upstream end of the pipe was raised above the channel bed by $0.145 \mathrm{~m}$, as shown in Fig. 5. Changes in the slope of the culvert barrel could be achieved by raising or lowering the outlet of the culvert to a pre-designated level. In addition to the three components of velocity, the depth of flows $H$ upstream of the culvert was measured with point gauges. Tail water was controlled by a hinge installed at the downstream end of the open channel. The culvert model was designed and manufactured at the Gdańsk University of Technology.

\section{Scope of Tests}

Tests were conducted for two standard inlet types of culvert, which are commonly used for the management and conveyance of storm water runoff throughout the roadway system. A multitude of different inlet configurations are used in culvert barrels. These include both prefabricated and constructed-in-place installations, such as projecting culvert barrels, cast-in-place concrete head walls, pre-cast or prefabricated end sections, and culvert ends mitered to conform to the fill slope. The most economical and generally used solution is the projecting culvert barrel. This inlet configuration could also induce scour if not well designed, and therefore it had been selected for experiments. This paper reports the results of tests on a $0.1 \mathrm{~m}$ diameter pipe culvert for discharges of $0.010 \mathrm{~m}^{3} / \mathrm{s}$ and two inlets: with the pipe projecting $0.1 \mathrm{~m}$ off the head wall and with the pipe set flush with the vertical plate (Fig. 3).

(a)

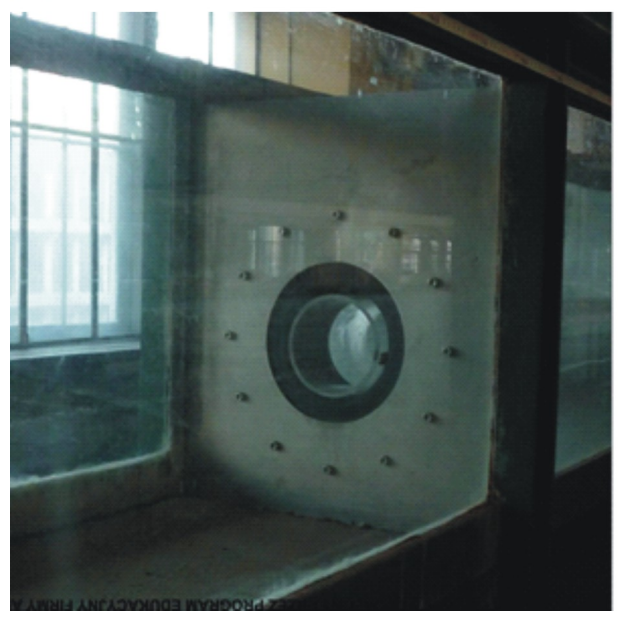

(b)

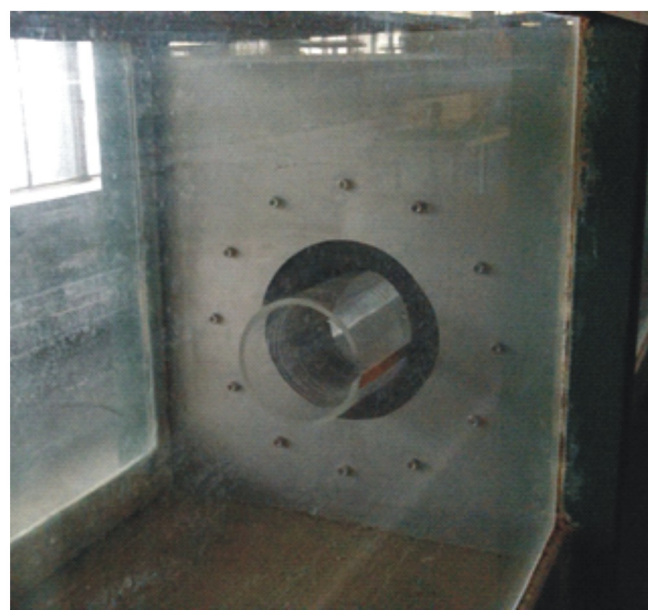

Fig. 3. Culvert inlet treatments: (a) vertical head wall end, (b) projecting end 
The discharge was selected in such a way as to ensure a head water elevation that prototype culverts might be exposed to during times of flooding. The prior discharge resulted in the culvert being surcharged to a depth of $H / D=2.8$. The examined condition, according to the U.S. Bureau of Reclamation (1987), is the submerged inlet case. This was also the maximum flow rate allowed in the laboratory channel with the culvert installed. Further increase in the discharge would have caused water to flow over the channel sidewalls. The culvert barrel slope was set to $0.17 \%$, causing a supercritical flow condition in the culver pipe. Tail water was set up above the outlet level to satisfy the case of a fully submerged outlet (full flow condition, Schall et al 2012).

\section{Acoustic Doppler Velocimeter Metrology}

A down-facing acoustic Doppler velocimeter (ADV) was used to investigate the velocity field at the culvert inlet. The SonTek 10-MHz ADV (Acoustic Doppler Velocimeter) is a versatile, high-precision instrument used to measure 3D water velocity. The ADV is designed to record instantaneous velocity components at a single-point with a relatively high frequency. Measurements are performed by gauging the velocity of particles in a remote sampling volume on the basis of the Doppler shift effect, which means that, for a stationary receiver, the sound waves reflected by the moving target are seen as being emitted by a moving source (Lemmin and Rolland 1997). The probe head includes one transmitter and three receivers (Fig. 4). The remote sampling volume is located $5 \mathrm{~cm}$ from the tip of the transmitter, which must be submerged, and therefore velocities could only be measured to within $5.5 \mathrm{~cm}$ of the water surface.

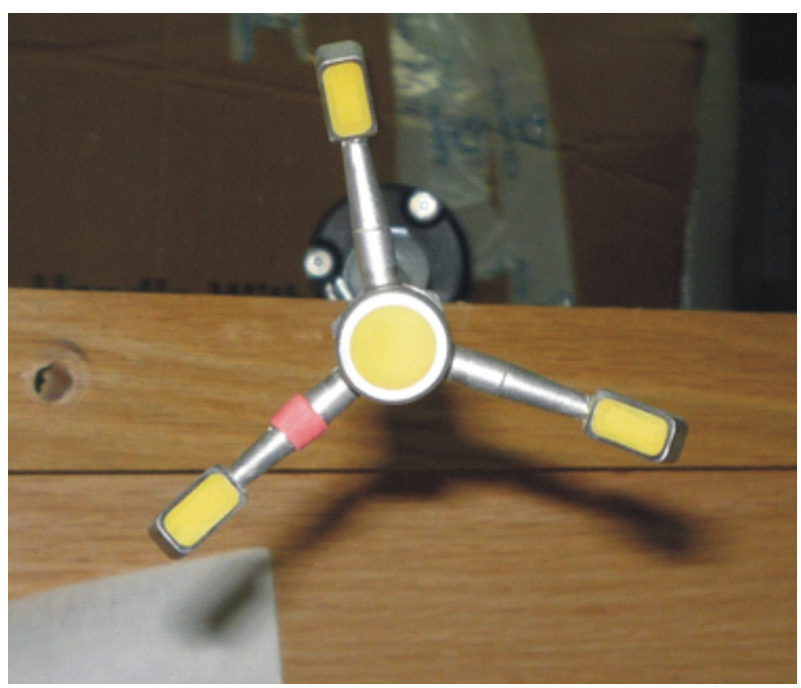

Fig. 4. Head of the acoustic Doppler velocimeter (one transmitter and three receivers) used in the experiments 
Several researchers have pointed out that the velocity field in the culvert may be symmetric, and therefore they limited their measurements to one half of the channel cross section (Day 1997, Hunt et al 2012, Liriano et al 2002). In the current study, possible local effects could affect the flow velocity, causing a non-uniform distribution in the channel.Therefore, velocity measurements were carried out in the entire cross section. In the first experiment, the first three cross sections, where the data were collected, were set at the culvert radius apart, that is $0.05,0.1$ and $0.15 \mathrm{~m}$ upstream from the pipe inlet (Fig. 5a). For the next two cross sections, a distance of one diameter was used ( 0.25 and $0.35 \mathrm{~m}$ upstream from the culvert). The last cross section was set at a distance of $1.25 \mathrm{~m}$ from the inlet. The data were analyzed (Wielgat 2012), and the largest change in velocity was observed in the immediate vicinity of the culvert, whereas within a distance of two culvert diameters the velocity field was relatively uniform. Therefore, for the next experiment, samples were taken in the vicinity of the culvert inlet only in six cross sections, $0.05 \mathrm{~m}$ apart. The last two cross sections, 0.35 and $1.25 \mathrm{~m}$ upstream from the culvert, were skipped.

For the projecting barrel case, additional survey data were collected at the inlet (distance $0 \mathrm{~cm}$ ) and $3.5 \mathrm{~cm}$ upstream of the inlet (Fig. 5b). For the other case, with the barrel set flush with the headwall, such measurements were impossible due to equipment limitations. When used close to the channel side, the ADV can reliably operate to within 4-6 cm of the boundary. Therefore, velocity was measured to within $5 \mathrm{~cm}$ of the culvert plate only.

(a)

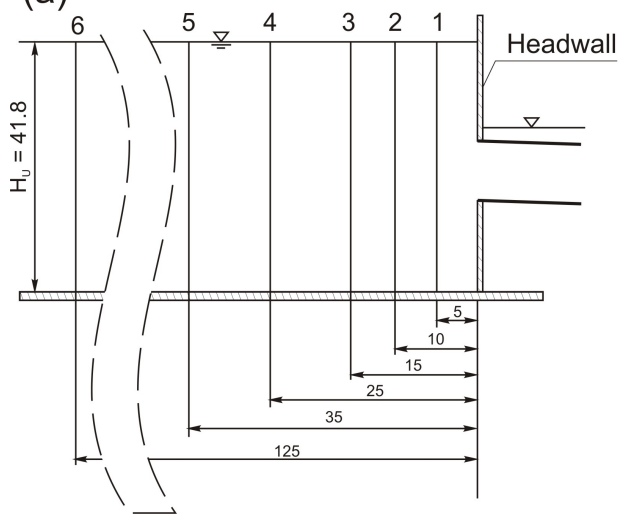

(b)

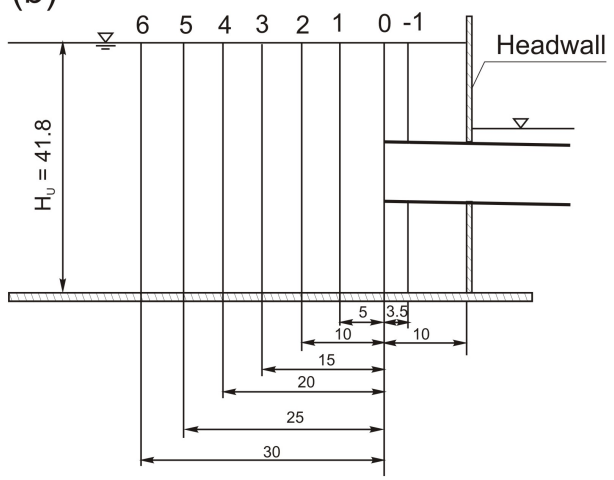

Fig. 5. Distribution of cross sections for (a) the vertical wall end and (b) the projecting end; dimensions in $\mathrm{cm}$

The ADV probe measured the water velocity $5 \mathrm{~cm}$ beneath the acoustic transmitter, which has to be submerged. Therefore the shallowest data point was set $5.5 \mathrm{~cm}$ beneath the water surface. For both experiments, the locations of sampling points were related to the pipe midpoint. Within one pipe diameter from the culvert centerline, the data were collected as dense as possible ( $3 \mathrm{~cm}$ apart), which was necessary to analyze 
the general nature of flow structures at the culvert inlet. This resulted in 56 velocity measurements per one cross section. For each point, 600 samples were taken with 50 $\mathrm{Hz}$ equipment frequency.

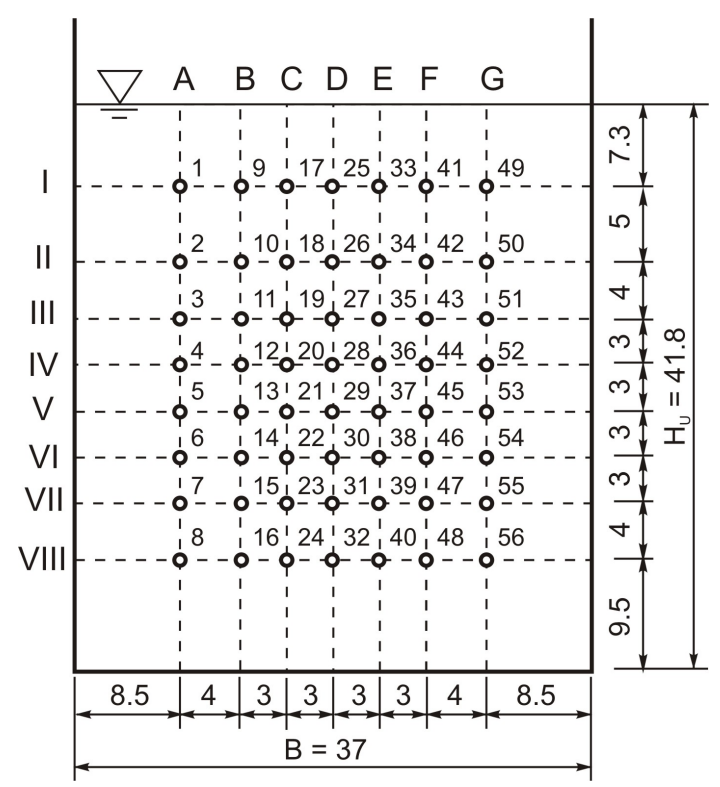

Fig. 6. Distribution of velocity measurement points in a cross section; point 29 is located at the culvert centerline (dimensions in $\mathrm{cm}$ )

\section{Results and Discussion}

Experimental results in the form of velocity vectors are presented in figures below. Fig. 7 shows the centerline velocity field in the direct vicinity of the culvert inlet for both experiments. For the case with the culvert barrel set flush with the plate, the vertical velocity close to the channel bed makes a significant contribution to the fluid motion. Up to 2 pipe diameters from the culvert inlet, the vertical velocity is in a range from 13 to 65 percent of the velocity magnitude. Further upstream, the effect disappears immediately, and the vertical velocity is almost negligible (5\% of velocity magnitude).

For the case of the culvert inlet structure in the form of a projecting barrel, the velocity distribution at the inlet is presented in Fig. 7b. The construction of the culvert with a projecting barrel caused vortex formation at the inlet. In the cross section located 0.35 pipe diameter downstream of the inlet, negative longitudinal velocity occurs. This phenomenon may result in the erosion of the embankment and scour, leading to the destruction of the culvert. Velocity conditions close to the channel bed are very similar to those for the culvert barrel set flush with the vertical wall. There are some differences caused by the vortex structure, such as the fact that the vertical fluid 
(a)

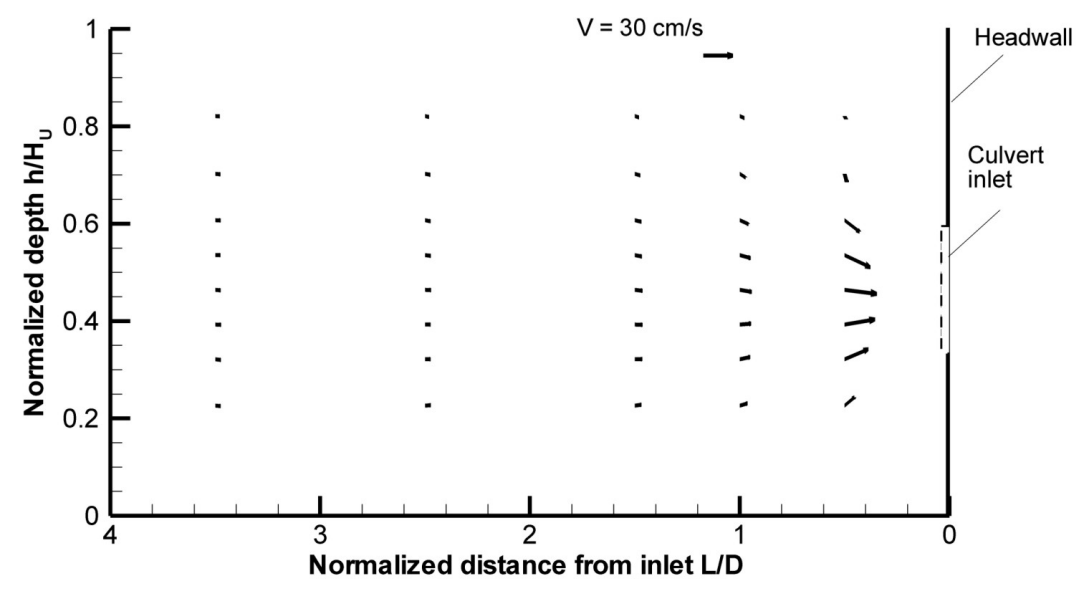

(b)

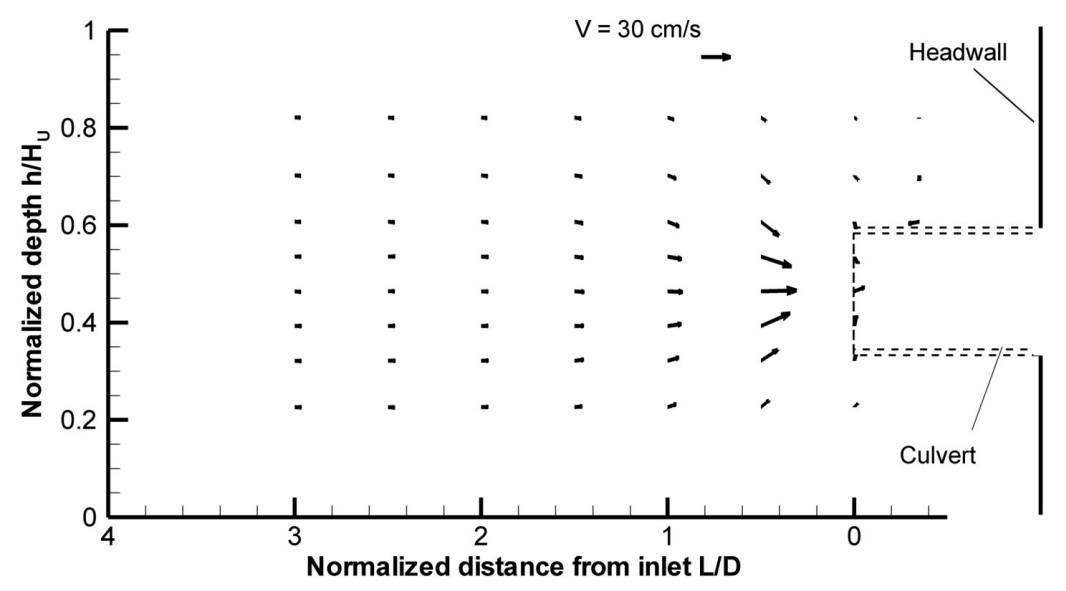

Fig. 7. Vectors of the longitudinal and vertical components of velocity in the $(z, x)$ plane at $y=0.5 B$ (channel centerline); (a) the case with the vertical headwall and (b) the case with a projecting culvert barrel; NOTE! data at 0 distance were collected at $y=0.34 B$

velocity rises slightly more slowly in the immediate vicinity of the culvert entrance. Beyond a distance of 2 pipe diameters from the inlet, the vertical velocity is close to 0 (less than $1 \%$ of velocity magnitude).

Fig. 8 shows horizontal vector velocity plots of the flow velocity field measured in the plane at the pipe centerline $\left(h=0.46 H_{u}\right)$. The velocity field similar to vertical component near the inlet can be observed in the plane view plot. In the immediately vicinity of the pipe inlet,the velocity vectors are turned towards the culvert entrance. The further from the barrel, the larger contribution of the cross-stream component is observed. The effect disappears over a 2 diameter distance from the culvert entrance. For the projecting barrel case, additional survey data were collected at the inlet (dis- 
(a)

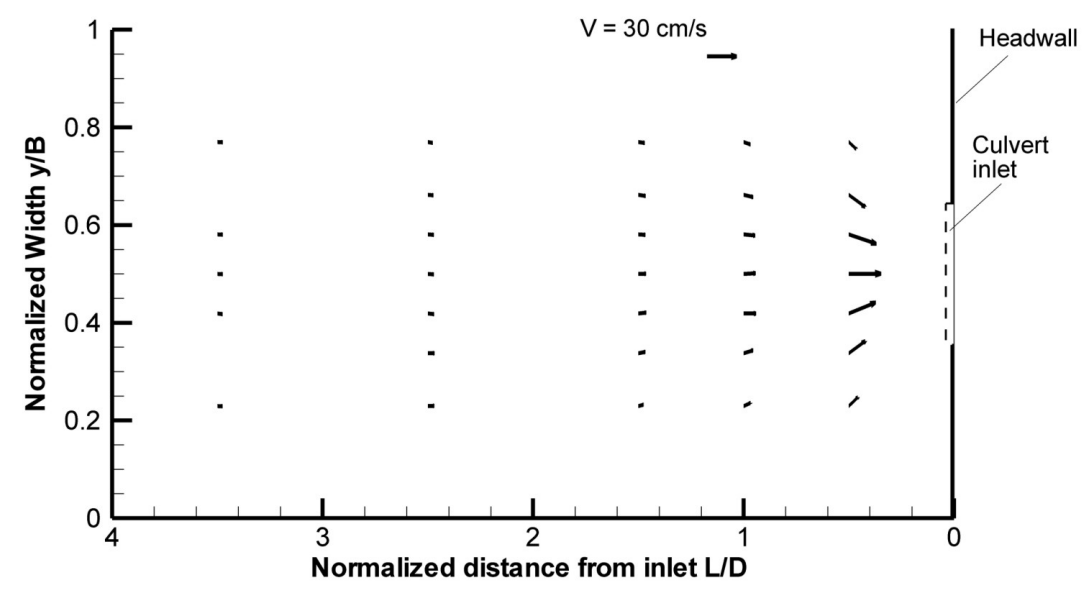

(b)

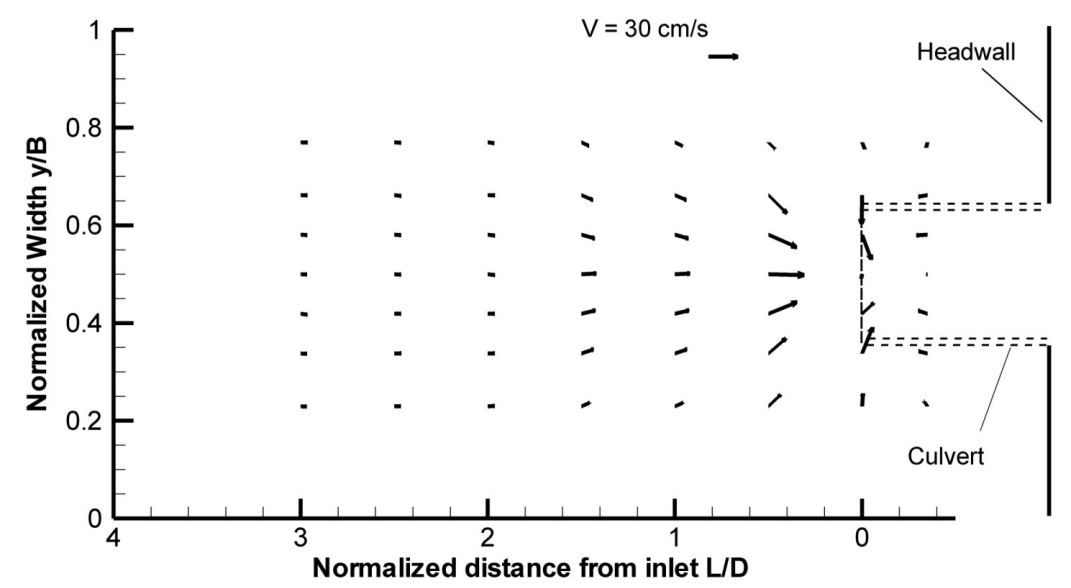

Fig. 8. Vectors of the longitudinal and cross-stream components of velocity in the $(x, y)$ plane at $h=0.46 H_{u}$ (culvert pipe centerline); (a) the case with the vertical headwall and (b) the case with a projecting culvert barrel; NOTE! Data at distance 0 and $-0.35 D$ from the entrance were collected at $h=0.61 H_{u}$

tance $0 \mathrm{~cm}$ ) and $3.5 \mathrm{~cm}$ downstream of the inlet. The data show a vortex structure in the zone adjacent to the exposed pipe. In these pockets, flow is directed toward the culvert, which is clearly seen from the longitudinal velocity to zero at the inlet cross section and from the rotating flow in the opposite direction at the cross section located downstream of the inlet. This may result in scour of the culvert embankment. For the other case, with the barrel set flush with the headwall, no negative flow at the inlet was observed.

A comparison of turbulence strength for both culvert inlet cases is presented in Figs. 9 and 10. The plots present turbulence in the centerline of the channel $(y=0.5 B)$, 


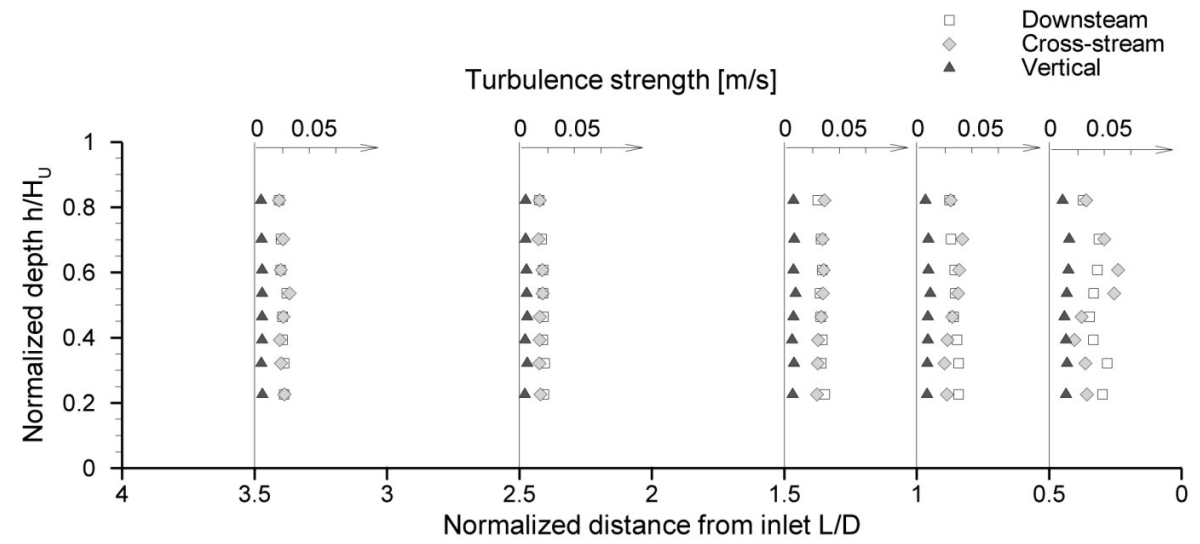

Fig. 9. Turbulence intensity in the $(z, x)$ plane at $y=0.5 B$ (channel centerline); the case with the vertical headwall

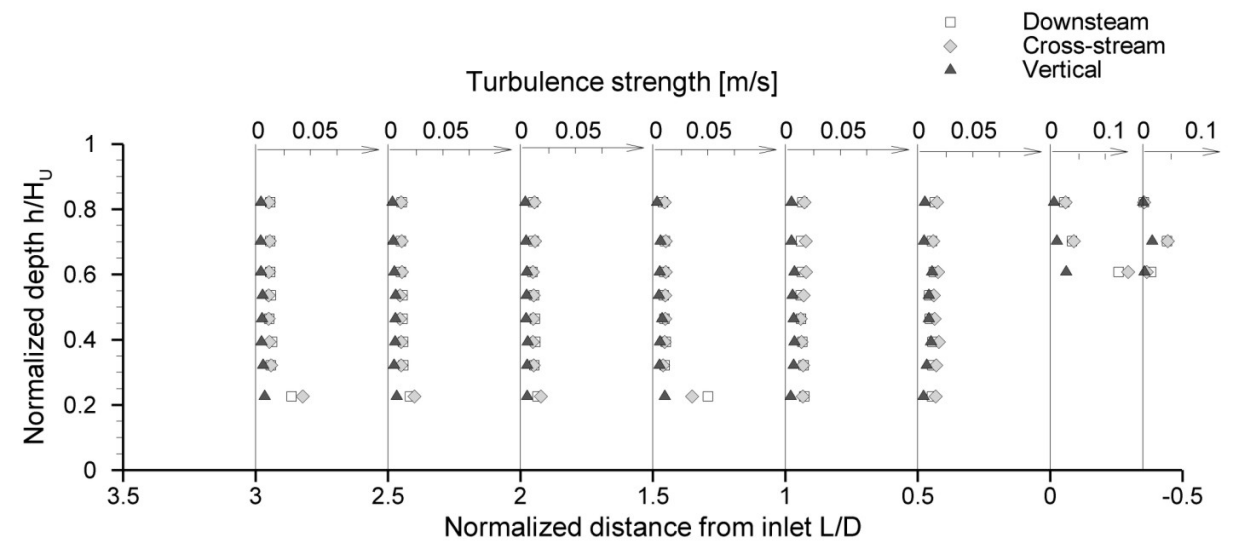

Fig. 10. Turbulence intensity in the $(z, x)$ plane at $y=0.5 B$ (channel centerline); the case with a projecting culvert barrel; NOTE! The stress scale at 0 and -0.35 pipe diameter distances is divided by 2

so the contribution of the cross-stream velocity component is negligible. Turbulence strength has been calculated from:

$$
T_{x}=\sqrt{\overline{\left(u^{\prime}\right)^{2}}}, \quad T_{y}=\sqrt{\overline{\left(v^{\prime}\right)^{2}}}, \quad T_{x}=\sqrt{\overline{\left(w^{\prime}\right)^{2}}},
$$

where $u^{\prime}, v^{\prime}$, and $w^{\prime}$ are the fluctuating components of velocities $[\mathrm{m} / \mathrm{s}]$ in the downstream, cross-stream, and vertical directions, respectively; an overbar is used to denote a time average. In theory, the velocity record is continuous, and the mean can be evaluated through integration. In practice, however,the measured velocity records 
are a series of discrete points, $u_{i}$. Therefore, equations (1) can be rewritten by using root-mean-square values, which by definition is the standard deviation of a set of "random" velocity fluctuations, $u_{i}^{\prime}$. Similar definitions apply to the lateral and vertical velocities, $v(t)$ and $w(t)$.

$$
\begin{aligned}
& T_{x}=\sqrt{\overline{\left(u_{i}^{\prime}\right)^{2}}}=\left[\frac{1}{N} \sum_{i=1}^{N}\left(u_{i}-U_{0}\right)^{2}\right]^{1 / 2}, \\
& T_{y}=\sqrt{\overline{\left(v_{i}^{\prime}\right)^{2}}}=\left[\frac{1}{N} \sum_{i=1}^{N}\left(v_{i}-V_{0}\right)^{2}\right]^{1 / 2}, \\
& T_{z}=\sqrt{\overline{\left(w_{i}^{\prime}\right)^{2}}}=\left[\frac{1}{N} \sum_{i=1}^{N}\left(w_{i}-W_{0}\right)^{2}\right]^{1 / 2} .
\end{aligned}
$$

$U_{0}, V_{0}$, and $W_{0}$ are time-averaged longitudinal components of water velocity $[\mathrm{m} / \mathrm{s}] ; u_{i}, v_{i}$ and $w_{i}$ are the instantaneous longitudinal, cross-stream, and vertical components of water velocity $[\mathrm{m} / \mathrm{s}]$. The calculated turbulence strength is presented in the $(z, x)$ plane at the channel centerline in Figs. 9 and 10. Three-dimensional velocity measurements showed the isotropic turbulence strength in the $(x, y)$ plane with $u^{\prime} \approx 1.0 v^{\prime}$ and the non-isotropic turbulence strength in the $(x, z)$ plane with $u^{\prime} \approx 2.9 w^{\prime}$. Two zones of turbulence can be distinguished: upstream of the culvert entrance and within a distance of one pipe diameter from the inlet. In the first zone, for both experiments, the profiles showed a uniform distribution of the turbulence strength in the channel upstream of the culvert. While turbulence is generated by the shear, stronger shear appears at the channel bed. This is evident in profiles of turbulence strength within a boundary layer, as shown in Fig. 10, for profiles located at a distance of 1.5 pipe diameter and greater.

Turbulence distribution changed in the vicinity of the culvert entrance. It increased the closer to the pipe inlet, forming a profile similar to turbulent velocity measured across a jet (Mih and Hooley 1972). The profiles are self-similar when normalized by the centerline velocity, $U_{C L}$. The maximum turbulence level occurs at the positions of the maximum shear. At the centerline $\left(h=0.46 H_{u}\right)$, the shear is zero $(\partial u / \partial y=0)$, and the turbulence strength is diminished (Fig. 11). A peak in both the downstream and cross-stream turbulences occurred in profiles at the culvert inlet close to the pipe walls. It is shown in profiles up to a distance of 1 pipe diameter. Beyond this distance, the turbulence strength decreased as the jet curved away from the pipe centerline, and the maximum value is observed at random locations, sometimes further from the pipe walls. This indicates a high potential for embankment scouring if aprojecting barrel is used.

The time-averaged local Reynolds stress at a point was determined using (Bennett and Best 1995): 

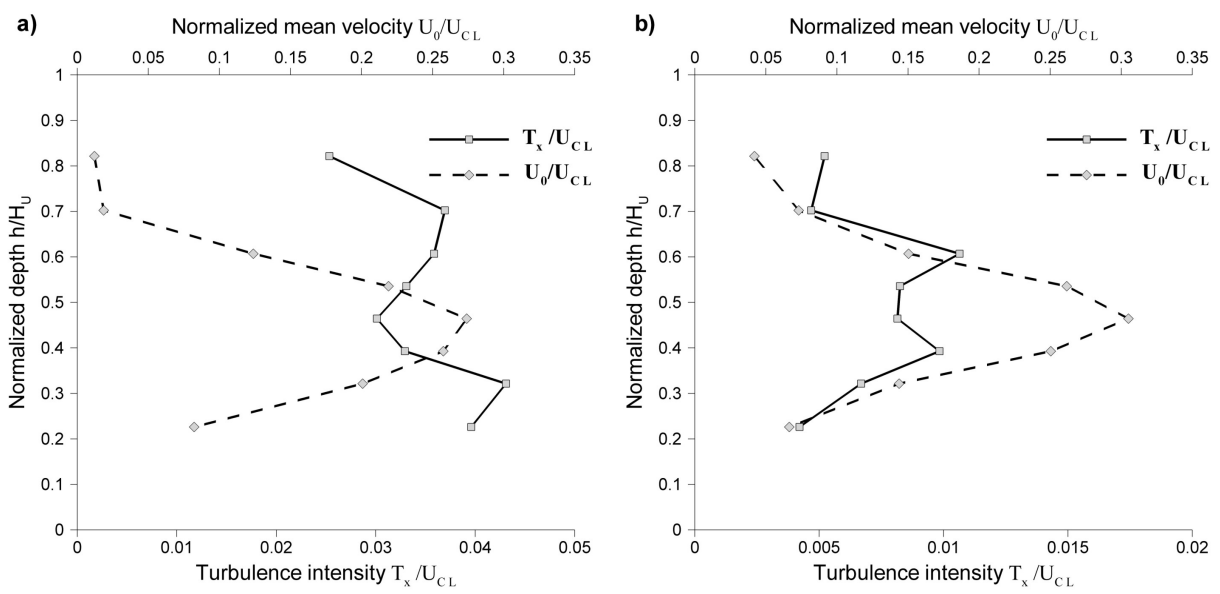

Fig. 11. Normalized turbulence and mean velocity at the 0.5 pipe diameter distance from the culvert entrance for (a) the vertical headwall case and (b) the projecting barrel case

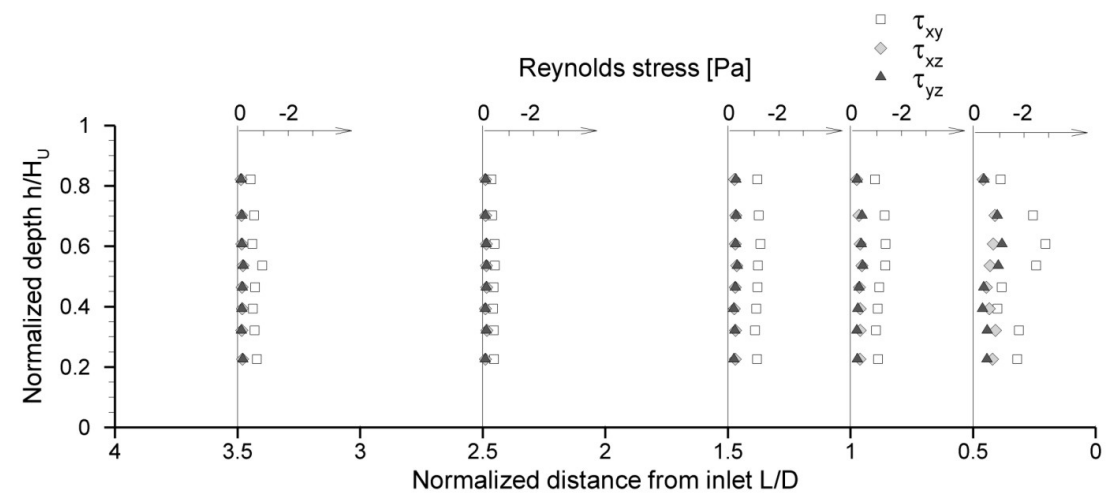

Fig. 12. Reynolds stresses in the $(z, x)$ plane at $y=0.5 B$ (channel centerline); the case with the vertical headwall

$$
\begin{aligned}
& \tau_{x y}=-\rho \overline{u^{\prime} v^{\prime}}=-\rho \frac{1}{N} \sum_{i=1}^{N}\left(u_{i}-U_{0}\right)\left(v_{i}-V_{0}\right), \\
& \tau_{x z}=-\rho \overline{u^{\prime} w^{\prime}}=-\rho \frac{1}{N} \sum_{i=1}^{N}\left(u_{i}-U_{0}\right)\left(w-W_{0}\right), \\
& \tau_{y z}=-\rho \overline{v^{\prime} w^{\prime}}=-\rho \frac{1}{N} \sum_{i=1}^{N}\left(v_{i}-V_{0}\right)\left(w-W_{0}\right) .
\end{aligned}
$$

where $r\left[\mathrm{~kg} / \mathrm{m}^{3}\right]$ is a fluid density. The profiles of Reynolds stresses in the channel centerline for both experiments are presented in Figs. 12 and 13. Similar to turbulence 


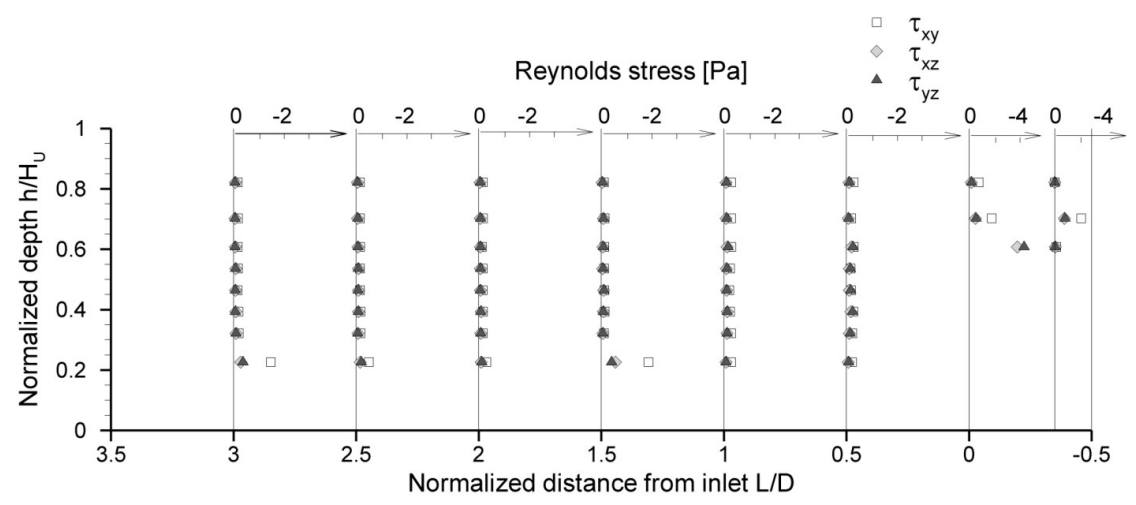

Fig. 13. Reynolds stresses in the $(z, x)$ plane at $y=0.5 B$ (channel centerline); the case with a projecting culvert barrel; NOTE! The stress scale at 0 and -0.35 pipe diameter distances is divided by 2

strength, the zone within one pipe diameter from culvert inlet is apparently different from the rest of the channel. The highest stresses are observed in areas adjacent to the exposed pipe and directly upstream of the inlet. The magnitude of stress exceeds 3 $\mathrm{Pa}$, which is a considerable value and may cause scouring in these areas. In addition, high stresses are observed close to the channel bed, where $2 \mathrm{~Pa}$ shear was recorded.

\section{Conclusions}

The results obtained byADV measurements upstream of the pipe culvert demonstrate the following issues:

1. In the zone within one culvert diameter from the culvert entrance all velocity components increase rapidly.

2. A projecting barrel inlet causes eddies at the culvert entrance. Vortex structures form in the area adjacent to exposed culvert barrel.Negative flow will form in these pockets, which may cause embankment scouring.

3. The flow in both cases is similar to the flow field for a negative turbulent jet discharging into a fluid of the same density. At distances greater than 2.0 times the culvert diameter, the flow exhibits normal velocity and turbulence intensity profiles.

\section{Acknowledgments}

The authors would like to thank the technical staff at the department for their valuable assistance in preparing the experimental facilities. The ADV instrument was purchased on research grant N N523 745840 from the National Science Centre. 


\section{References}

Abt S. R., Ruff J. F., Doehring F. K. (1985) Culvert slope effects on outlet scour, Journal of Hydraulic Engineering, 111 (10), 1363-1367.

Abt S. R., Ruff J. F., Doehring F.K., Donnell C. A. (1987) Influence of culvert shape on outlet scour, Journal of Hydraulic Engineering, 113 (2), 393-400.

Bennett S. J., Best J. L. (1995) Mean flow and turbulence structure over fixed, two-dimensional dunes: implications for sediment transport and bedform stability, Sedimentology, 42 (3) , 491-514.

Day R. A. (1997) Preliminary observations of turbulent flow at culvert inlets, J. Hydraul. Eng., 123 (2), $116-124$.

Doehring F. K., Abt S. R. (1994) Drop height influence on outlet scour, J. Hydraul. Eng., 120 (12), 1470-1476.

Ead S. A., Rajaratnam N., Katopodis C., Ade F. (2000) Turbulent Open-Channel Flow in Circular Corrugated Culverts, J. Hydraul. Eng., 126 (10), 750-757.

Feurich R., Boubée J., Olsen N. R. B. (2012) Improvement of fish passage in culverts using CFD, Ecological Engineering, 47, 1-8.

House M. R., Pyles M. R., White D. (2005) Velocity distributions in streambed simulation culverts used for fish passage, Journal of the American Water Resources Association, 41 (1), 209-217.

Hunt M., Shawn Clark S., Tkach R. (2012) Velocity distributions near the inlet of corrugated steel pipe culverts, Canadian Journal of Civil Engineering, 39 (12), 1243-1251, 10.1139/12012-112.

Kubrak E., Kubrak J. (2004) Technical Hydraulics: examples of calculations, Wyd. SGGW, Warszawa (in Polish).

Lemmin U. and Rolland T. (1997) Acoustic velocity profiler for laboratory and field studies, Journal of Hydraulic Engineering, 123 (12), 1089-1099.

Liriano S. L., Day R. A., White W. R. (2002) Scour at culvert outlets as influenced by the turbulent flow structure, Journal of Hydraulic Research, 40 (3), 367-376.

Mays L. W. (2005), Water Resources Engineering, John Willey and Sons, New York.

Mih W. C., Hooley J. A. (1972) Mean and turbulent velocities for plane jet, J. of Hyd. Div., Proc. ASCE, 98 (HY7), 1275-1294.

Schall J. D., Thompson P. L., Zerges S. M., Kilgore R. T., Morris J. L. (2012) Hydraulic design of highway culverts, Report No. FHWA-HIF-12-026 HDS 5, U.S. Department of Transportation, Federal Highway Administration.

Shields A. (1936) Application of similarity principles and turbulence research to bed-load movement, Heft 26 (Rep.) Mitt. der Preuss, Versuchsamt für Wasserbau und Schiffbau, Berlin, Translated by Ott W. P. and van Uchelen J. C.

Szpakowski W. (2013) Estimation of real capacity of road culvert, Drogownictwo, 6, 189-192 (in Polish).

U.S. Bureau of Reclamation (1987) Design of small dams, 3rd edition, U.S. Government Printing Office Washington DC.

Van Rijn L. C. (1984) Sediment transport. Part I: Bed load transport, J. Hydraul. Eng., 110 (10), 1431-1456.

Wielgat P. (2012) Three-dimensional flow field in an open channel at the culvert inlet, Undergraduate thesis, Gdańsk University of Technology (in Polish). 